\section{The use of videoconferencing in nursing for people in their homes}

\author{
Bente Nordtug, Hildfrid V. Brataas, \\ Lisbeth O. Rygg
}

Faculty of Nursing and Health Sciences, Nord University, Norway

\begin{abstract}
The aim of this literature review is to bring to the forefront knowledge about the suitability of videoconferencing (VC) in nursing for patients and their families living at home. A systematic literature review that included studies of $\mathrm{VC}$ in nursing care. Inclusion criteria were original studies relevant to concept of study. Computerized bibliographic databases (PubMed, CINAHL and PsycINFO) were searched from January 2008 to October 2016. In total, 325 articles were identified. Eight articles (1539 participants) met the inclusion criteria, and were finally included. The eight articles covered $\mathrm{VC}$ used in follow-up care for patients living in their homes after surgery, postpartum, chronic illnesses, families with premature infants, and children with cancer. A conventional content analysis was conducted. The results show that the success of VC depends on satisfying network access. Nurses as well as patients thought VC was similar to meeting in person. VC seems to support person-centred nursing, promote self-management and motivate patients and families to engage in their health. The use of $\mathrm{VC}$ requires further organization of the nursing practice. The study indicates that $\mathrm{VC}$ can be a suitable alternative to traditional nursing follow-up when network access and technology function properly and the nursing service is well organized. VC seems to underpin person-centred nursing. Knowledge gaps identified, more research needed as bases for assessment of VC suitability in nursing for individual persons in different treatment situations.
\end{abstract}

\section{Introduction}

\section{What is known, what this study adds}

What is already known:

- There is little research about videoconferencing (VC) in nursing;

- The rate of chronic diseases is likely to rise as the population ages;

- There will be less nursing capacity available in the future;

- Innovation in nursing will be needed.
What this study adds:

- VC seems suitable in person-centred nursing supporting self-management;

- Functional technology and training is a prerequisite for $\mathrm{VC}$ in nursing;

- VC requires organizational adaptions in nursing.

$\mathrm{VC}$ is interaction using technology that includes voice and video camera communication, allowing people in different locations to exchange information verbally and visually in real-time. ${ }^{1}$ Information- and communication technology encompasses telemedicine and home telecare. ${ }^{2,3} \mathrm{VC}$ is based on connection to the Internet, by wireless signals or cable and application software, as, for instance, Skype or FaceTime, designed for $\mathrm{VC}$ use on personal computers, tablets or mobile phones. In nursing, VC can be used for several purposes, such as monitoring of patients, listening to them and their concerns, observing their physical and mental state, managing their symptoms, instructing and teaching them, and coordinating with other parts of the healthcare system. ${ }^{3,4}$

In the years to come, public health resources will be limited, and home-based care will increase. ${ }^{5}$ For example, in Norway, a small European country with about 5.2 million residents, Statistics Norway reports about 83,000 persons were working in the field of nursing and caregiving in 2010, while the predicted need for 2030 is 144,000. In 2010 there were about 3,000 vacant posts, and by 2030 the forecast is that there will be a shortage of 20,000 nursing and care staff. ${ }^{6}$ Between 2015 and 2030, the number of people aged 60 years or older is expected to increase by 56 percent. The number of people age 80 years or over is growing even faster. The older population will be tripled from 2015 to 2050 (from 125 million to 434 million). ${ }^{7}$ The rate of chronic disease is likely to rise as the population ages. ${ }^{89}$ Also, patients may be discharged from hospitals more quickly than today, and will therefore need a higher degree of support in their homes. ${ }^{10,11}$ Statistical forecasts show a possibility that there will be fewer nurses available, and home-dwelling patients and relatives will have less access to home-based care than they do currently. ${ }^{12}$ Nevertheless, an increasing number of patients and their caregiving relatives may be in need of nursing support to empower their self-efficacy and self-management in a variety of health situations. ${ }^{13-15}$

To meet future challenges, $\mathrm{VC}$ can be a tool for home-based nursing. ${ }^{16}$ In that respect, person-centred care provided by VC may motivate patients and relatives to increase their self-management. ${ }^{17-19}$ Person-
Correspondence: Bente Nordtug, Faculty of Nursing and Health Sciences, Nord University Hogskolevegen 27, Nord Universitet, 7600 Levanger, Norway.

E-mail: bente.nordtug@nord.no

Key words: Communication; Home dwelling; Nursing recipients; Person-centred care; Telecare; Videoconferencing.

Contributions: the authors contributed equally.

Conflict of interest: the authors declare no potential conflict of interest.

Funding: Nord University.

Received for publication: 20 April 2017.

Revision received: 23 January 2018.

Accepted for publication: 25 June 2018.

This work is licensed under a Creative Commons Attribution NonCommercial 4.0 License (CC BY-NC 4.0).

CCopyright B. Nordtug et al., 2018

Licensee PAGEPress, Italy

Nursing Reports 2018; 8:6761

doi:10.4081/nursrep.2018.6761

centred care provide outcomes such as experience of involvement in care, a feeling of well-being, and positive experiences of a therapeutic and collaborative nursing culture. ${ }^{20}$ Person-centred care takes into consideration people's values, family situations, desires, social conditions, and lifestyles; sees the patients as individuals; and emphasizes cooperation in the development of appropriate health solutions. ${ }^{20-22}$ Such care is marked by a way of thinking and acting that look at people using health and social services as equal partners in planning, developing and monitoring care, this in order to make sure that the care meets the people's needs. This means ensuring that patients and their families are at the centre of decisions, perceived as experts on their lives, and working alongside professionals to get the best results (Health Innovation Network; www.hin-southlondon-org).

Using VC, person-centred nursing may influence people's intrinsic motivation for self-management in their health situations. ${ }^{23,24}$ Self-management may enable persons to make informed choices. ${ }^{24}$ Research indicates that positive changes in activation is related to positive changes in a variety of self-management health behaviours among patients having chronic conditions such as diabetes, heart disease or chronic obstructive pulmonary disease. ${ }^{25}$ An intervention combining self-management support and 
collaborative care over time (12 months) showed significant improvement in the confidence of the ability to follow medical regimes and maintain lifestyle changes. ${ }^{26}$ Wildevuur and Simonse ${ }^{27}$ reviewed literature to find what communication technology interventions have been used to support patients and healthcare professionals in person-centred care management of five chronic diseases - diabetes mellitus, cardiovascular disease, chronic respiratory disease, cancer, and stroke. They found that most of these patients used communication technology primarily for self-measurement of physiological body tests. Of the 350 identified studies, 60 indicated a positive impact from the use of personalized communication technology on empowerment, physical condition, health-related quality of life, and self-efficacy. This review found no clear answers to either clinical, organizational or at hospitalization outcomes, but identified was an increase in contact between patients and health personnel. ${ }^{27}$ Some studies indicate that VC is seen as a practical tool for healthcare delivery. ${ }^{28}$ Few interventions involved a complete approach to personcentred care, and there was no distinction between different forms of internet-based communication in this review. ${ }^{27} \mathrm{VC}$ may represent a potential tool to solve some of the future challenges in healthcare. Through an increased use of VC, a limited number of nurses may be able to care for more patients both in short- and long-term care. ${ }^{10,29,30} \mathrm{VC}$ may also decrease travel time and expenses for both nurses, patients and their families, especially in rural or remote areas. ${ }^{31}$ Preliminary evidence shows VC nursing to be useful for home residents, although further research is needed to obtain more knowledge of user experiences. ${ }^{28}$ Seen from a person-centred perspective, there is a need for more knowledge about people's experiences of benefits and obstacles using VC in nursing. The aim of this study was to review research papers describing suitability of video conferencing in nursing for patients and their families living at home.

\section{Methods of research}

A systematic literature review retrieving studies about suitability of videoconferencing in nursing for people living at home. Included articles were content analysed.

\section{Participants and communication sit- uations}

Inclusions:

- Research articles where the intervention were $\mathrm{VC}$, using both voice and video camera in nursing for patients and their families living at home.

- Articles on research the use of VC in care provided by personnel in both hospitals and community care.

- Nursing for people in all ages, both sexes, and with chronic illnesses or need of nursing follow-up after hospital stay.

- Nurses were included regardless of previous knowledge or experience with use of VC.

Excluded were studies of other e-Health interventions than $\mathrm{VC}$, and studies of other health care professionals than nurses.

\section{Search strategy and study selection}

A computerized bibliographic search was conducted. Data sources were PubMed, CINAHL, and PsycINFO. Used search terms are shown in Box 1 (in the Appendix). Database searches done in 2017, the searches were limited to articles published between 2008 and 2016, this to review the most recently published studies. Articles included in the review were original, peerreviewed research articles written in English or Scandinavian that pertained to either adults or children, or to relatives and careers, with VC in nursing for homedwelling people. The three reviewers independently scanned the search results for relevant titles, abstract sections, or keywords. Full articles meeting inclusion criteria then retrieved for further assessment. If there were doubts about whether a study should be included, all three reviewers assessed inclusion of the study in the literature review.

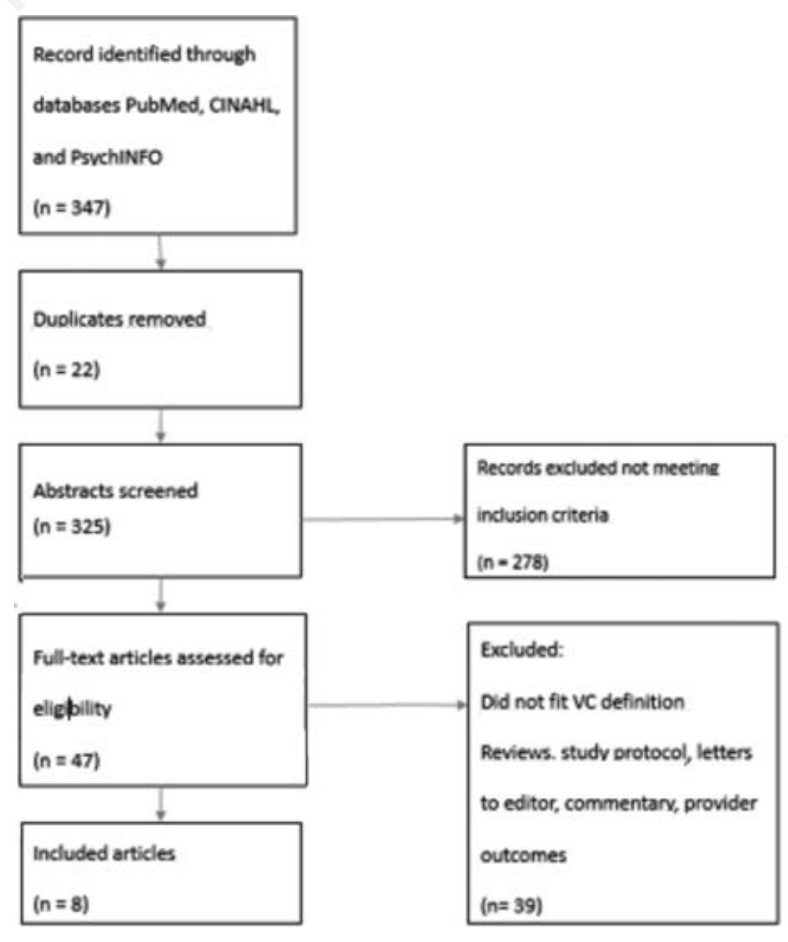

Figure 1. Article selection process.

\section{Analyses}

The articles' results were analysed using conventional content analysis. ${ }^{32,33}$ First, each of the researchers read all eight articles in full to obtain a sense of the field of study. Next, meaning units from the result sections in the eight articles were coded into descriptive codes according to the content. Then, the codes were sorted into subcategories, after which the subcategories were further abstracted into categories. Categories describing the VC phenomenon by differences and similarities of experiences were developed. Interpretations were done in relation to the aim of the study.

\section{Results}

A total of 347 articles were found, with 148 in PubMed, 196 in CINAHL, and 3 in PsycINFO. Twenty-two duplicates were excluded before the abstracts were screened. All abstracts of selected articles were evaluated to see if they fulfilled the inclusion criteria, resulting in 33 articles from PubMed, 14 articles from CINAHL, and none from PsycINFO. Thirty-nine records not meeting the inclusion criteria were further excluded. Then, the remaining eight articles were reviewed for accuracy. This process is illustrated in Figure 1. Of the eight articles included in this review, two were from the United States, one was from Australia, four were from Sweden, and 
the remaining one was from Spain. Except for two randomized controlled trials and one qualitative article, the articles were pilot studies with small samples. Of them, two were qualitative, two were quantitative, and two utilized mixed methods. Altogether, 1,539 respondents participated in the combined studies, including 1,401 post-partum women, 25 pairs of parents, 64 patients, one relative, five assistants and 22 nurses, including specialized nurses and midwives. Two articles included nurses' perspectives on the use of VC; two articles included the perspectives of the nurses and their patients; and the rest of the articles included only the patients' perspectives.

VC was used in home-care situations and follow-up appointments after a hospital stay. Included were VC applications in very different health situations: Follow-ups and appointments after major cancer surgery; ${ }^{34}$ postpartum, ${ }^{35-37}$ for patients having diabetes mellitus; ${ }^{38}$ for patients with chronic illness; ${ }^{39}$ for parents with premature infants; ${ }^{40}$ and for children with cancer. ${ }^{41}$ The literature review matrix, shown in Table 1, was guided by Mallow et al. ${ }^{42}$ and includes the names of the authors and publication years, country, aim, design, participants, and results.

Analyses led to three categories: VC technology, VC organization in nursing, and person-centred nursing, with subcategories presented in Table 2.

\section{Videoconferencing technology}

The VC technology category included the subcategories "access and equipment," and "training and use."

\section{Subcategory "access and equipment"}

Successful implementation of VC was heavily dependent on network access. A rapid development in the technology field showed growing use of online equipment. ${ }^{34}$ In 2008 a study showed blurred video problems for the first few minutes of $\mathrm{VC}$, due to simultaneously use of other internet devices ${ }^{41}$. Web access connections could still be problematic. ${ }^{34-36,38}$ Earlier the VC equipment was larger and heavier to carry compared with today. ${ }^{34,37,40}$ Problems relating to the quality of picture in $\mathrm{VC}$ were reported ten years ago..$^{36,37,40,41}$ Different technological problems may still occur, as spoiled videofeed for instance. ${ }^{34,39,40}$ Human mistakes, such as forgetting to turn the tablet signal off, were also reported.

\section{Subcategory "training and use"}

The need for sufficient information and training before the use of VC was an important aspect throughout the entirety of the period studied. ${ }^{34,36,37,40}$ Patients tended to be more accustomed to computer technology as they more often had their own computers. Thus training of $\mathrm{VC}$ use has become easier. ${ }^{34}$ However, patients needed technical support during interventions, even in recent years. ${ }^{35-37}$ Even so, patients rated the technology as being relatively easy to master both in 2007 as well as in $2016 .^{34,36,37}$

\section{Videoconferencing organization in nursing}

The second category concerns the organization of VC and includes the subcategories "contact time" and "privacy."

\section{Subcategory "contact time"}

VC was organized in different ways. Sometimes only the patients and families could initiate contact with a nurse when in need - in some studies at any time of the day or night, ${ }^{37,40}$ - in other cases only during daytime. ${ }^{35}$ More frequently, both nurses and patients were able to initiate contact. ${ }^{36,39,41}$ Fixed times for VC sessions ${ }^{38}$ with ad hoc possibilities in addition when necessary ${ }^{34}$ were also reported. VC provided possibility for flexibility, but planned use of VC seemed necessary. Nurses could be available via VC even while in hospital or in homes of other patients, this creating a short lag time between initiated contact and the actual VC meeting. It occurred difficulty for the patient or personal assistant to get into contact in real time. ${ }^{39}$ In this case, the technique functioned properly, but the nurse was unable to answer due to other more pressing nursing tasks. In an attempt to avoid disruption of work, one office developed a schedule of available VC times for the nurses. ${ }^{41}$ There was a need to structure VC sessions with regard to who should initiate contact when, how often, and where.

\section{Subcategory "privacy"}

Nurses preserved families' and patients' privacy by ensuring that others were not listening to or seeing their VC conversations. ${ }^{35,36,40}$ Occasional feelings of uneasy being observed by patients occurred among nurses. ${ }^{37,40}$ Families and patients controlled where VC took place in their own homes, that leading to little threat to their privacy. Some preferred VC over home visits due to this level of control, no longer feeling that they needed to prepare the house for a visitor before the arrival of a nurse. ${ }^{37,40}$

\section{Person-centred nursing}

This category included the subcategories "close collaboration", "assessment and follow-up", and "outcome".

\section{Subcategory "close collaboration"}

$\mathrm{VC}$ fostered close collaboration and was experienced as natural, promoting trust between patients, relatives, and nurses. ${ }^{37-39}$ In all studies, the nurses established contact with the patients and their families before the VC started. Compared to telephone contact, VC brought a richer and deeper dimension to the conversation by including body language. ${ }^{37-41}$ The nurses and families thought $\mathrm{VC}$ was quite similar to having a meeting in person, and distance became a non-issue. ${ }^{37,39,40}$ Seeing each others' faces on the screen made it easier for patients and their families, and also for the nurses, to understand the information they needed. Further, it eased the nurses' processes giving instructions and information.

\section{Subcategory “assessment and follow-up”}

Nurses tried to approach the patients and their families holistically through the $\mathrm{VC}$ system. VC was suitable in follow up of medical health problems, information provision, and discussion of patients' and families' emotions, needs, and wishes..$^{37,39-41}$ Families and patients adopted VC into their everyday lives more easily than timed physical contact at home or in a hospital. There was less planning for receiving visits in the home and no planning for a trip to the hospital. ${ }^{39}$ Patients and families across the board used VC only when in need, not for small talk, and regardless of time and place $35,36,39-41$ not bothering nurses needlessly.

\section{Subcategory "outcome"}

In general, health outcomes from VC were positive in all studies. Feeling of security and heightened care quality was a result from VC. Patients, assistants, and families experienced care via $\mathrm{VC}$ in such a way that they could solve breast-feeding problems or carry out treatment procedures in the home on their own, without the practical assistance of an onsite nurse. ${ }^{35,38,39} \mathrm{VC}$ promoted instruction and discussion on issues related to the health situation. VC conversations often were more to the point than consultations in ordinary care..$^{34,37,38} \mathrm{VC}$ consultations resulted in closer follow up for longer periods of time than ordinary care. ${ }^{35} \mathrm{VC}$ resulted in reduced travel time for nurses, patients, and families. Further, time was realised for more patient care ${ }^{35,37-41}$ One article explored quality impact of $\mathrm{VC}$ in nursing follow-up after complex surgery and early discharge from hospital. These findings showed that this kind of VC follow-up was more expensive and lasted longer than standard care plan. ${ }^{34}$ Early discharge after such surgery required a high degree of monitoring and advanced nursing care. 
Table 1. Literature review matrix.

\begin{tabular}{|c|c|c|}
\hline Authors & Country & Aim \\
\hline $\begin{array}{l}\text { Bensink et al. } \\
(2008)^{41}\end{array}$ & Australia & $\begin{array}{l}\text { To investigate } \\
\text { the feasibility } \\
\text { of videotelephone-based } \\
\text { support returning at home } \\
\text { first time after dignosed } \\
\text { and initial treatment } \\
\text { at hospital }\end{array}$ \\
\hline
\end{tabular}

\section{Design}

A qualitative pilot study

(three month) - analyses of

structured interviews

and cost-minimization.

Only hospital could initiate VC, not the families
Participants

Four nurses and seven families $20 \mathrm{VC}$

A random controlled study (three month) - analyses of quantitative biometric data and n-depth interviews. There were usually 30 minutes

VC weekly with the telehealth nurse close relationship with having access to online self-management tools or not

Lindberg, Sweden To describe parents'

Treatment group $\mathrm{n}=26$, control group $n=21$

Nine couples being new parents Christensson, $\quad$ experiences of VC when Öhrling $(2009)^{37}$ discharged early from a maternity unit

A pilot study

(12 month) -triangulation and analyses of descriptive quantitative and qualitative of narrative interviews. The parents could VC whenever they needed

\begin{tabular}{|c|c|c|}
\hline $\begin{array}{l}\text { Lindberg, } \\
\text { Axelsson, } \\
\text { Öhrling } \\
(2009)^{40}\end{array}$ & Sweden & $\begin{array}{l}\text { Describe the experience } \\
\text { of paediatric nurses' } \\
\text { use of VC in a neonatal } \\
\text { intensive care unit and } \\
\text { families at home }\end{array}$ \\
\hline
\end{tabular}

A pilot study (12 month)

- analyses of qualitative narrative interviews. The parents could VC when they needed

\section{Resp}

Respondents felt

confident with

1) the technology',

2) control of their privacy',

3) being face-to-face on the VC, and 4) worries and concerns met

10 paediatric nurses The nurses experienced smoother infants' transition from neonatal unit to homes.

VC helped to assess the overall situation, facilitate parent-infant, and provide security to the family

\begin{tabular}{|c|c|c|}
\hline $\begin{array}{l}\text { Lindberg, } \\
\text { Öhrling, } \\
\text { Christensson } \\
(2007)^{37}\end{array}$ & Sweden & $\begin{array}{l}\text { Describe midwives' } \\
\text { experiences using } \\
\text { VC supporting parents } \\
\text { discharged early after } \\
\text { childbirth }\end{array}$ \\
\hline
\end{tabular}

A pilot study (12 month) -triangulation and analyses of descriptive quantitative and qualitative semi-structured interviews. Only the parents could VC when they needed

\begin{tabular}{|c|c|c|}
\hline $\begin{array}{l}\text { Seguranyes } \\
\text { et al. } \\
(2014)^{35}\end{array}$ & Spain & $\begin{array}{l}\text { To compare the efficacy of } \\
\mathrm{VC} / \text { telephone care with } \\
\text { standard postpartum care }\end{array}$ \\
\hline
\end{tabular}

$\begin{array}{ll}\text { A random controlled } & \text { Intervention group } \\ \text { study (12 month) } & \mathrm{n}=683, \text { control group } \\ \text { - analyses of quantitative } & \mathrm{n}=718\end{array}$

data. The intervention group could VC when they needed

\section{Seven midwives $-23 \mathrm{VC}$}

The quality of sound and picture were good or very good. VC was easy to handle and useful when making assessments, and experienced as a valuable and fuctional complement to usual practice Breastfeeding and satisfaction
with midwives were similar in the two groups. Women using VC made fewer health centre visits, but had more often consultations with the midwifes compared to control group

\begin{tabular}{|c|c|c|}
\hline $\begin{array}{l}\text { Skär and } \\
\text { Söderberg } \\
(2011)^{39}\end{array}$ & Sweden & $\begin{array}{l}\text { To describe benefits } \\
\text { and limitations of VC use } \\
\text { in care of chronically } \\
\text { ill patients }\end{array}$ \\
\hline
\end{tabular}

A pilot study (seven month) - analyses of qualitative data from repeatad semi-structured interviews and logbook notes. All participant were allowed to $\mathrm{VC}$ whenever they needed

\begin{tabular}{|c|c|c|}
\hline $\begin{array}{l}\text { Katz et al. } \\
(2016)^{34}\end{array}$ & USA & $\begin{array}{l}\text { To investigate } \\
\text { the feasibility of VC } \\
\text { in postoperative } \\
\text { comprehensive recovery } \\
\text { after hospital discharge } \\
\text { of patients undergone } \\
\text { pancreatectomy }\end{array}$ \\
\hline
\end{tabular}

$\begin{array}{ll}\text { A pilot study (five weeks) } & 15 \text { patients } \\ \text { - analyses of quantitative data } & \text { Both patients, nurse, } \\ \text { All participant were } & \text { and assistant appreciated } \\ \text { allowed to VC whenever } & \text { being able to VC regardless } \\ \text { they needed } & \text { of time and place, which } \\ & \text { revealed feelings of safety } \\ & \text { and security. There were few } \\ & \text { technical problems. Using VC } \\ & \text { showed greater economic costs } \\ & \text { than standard pathway }\end{array}$

One district nurse, Both patients, nurse, one personal assistant, and assistant appreciated being two patients with able to $\mathrm{VC}$ regardless of time and chronic illnesses place, which revealed feelings of safety and security. There were few technical problems 


\section{Discussion}

The suitability of VC in nursing for people in their homes depended on three interrelated categories (Figure 2). Suitability was linked to technology prerequisites, and organizing of $\mathrm{VC}$ in care. These environment dimensions affected personcentred nursing. ${ }^{20}$ As Figure 2 illustrates, the technology selection and its functioning, and the VC user skills are matters of importance as prerequisites for person-centred nursing when using VC. Moreover, ways of organizing $\mathrm{VC}$ in nursing can either enable or inhibit suitability of $\mathrm{VC}$ in person-centred nursing. In person-centered nursing patients are considered as equal partners in planning, developing and monitoring care. ${ }^{20-22}$ This means that planning organizing should involve cooperation with patients on how to organize the care. Knowledge about such cooperation is lacking, and further research needed.

\section{Videoconferencing technology}

When technology functioned, VC allowed people to exchange information verbally and visually in real-time. ${ }^{1}$ Video quality was reported varying ten years ago. ${ }^{37,40,41}$ Since then, technology has advanced significantly both in equipment, network access and image quality. VC equipment has improved from being heavy, cumbersome, stationary computers to today's small handheld tablets. ${ }^{34,37,40}$ Nevertheless, the network access is still troublesome at times, and in some areas..$^{34,38}$ Since not everybody has the ability to use this tool yet, this can result in differences within populations in the offer of $\mathrm{VC}$ as treatment follow up in nursing. ${ }^{3}$ Usability of $\mathrm{VC}$ in person centered nursing presupposes reliable functioning of the technology at all times when the patients can contact. This to empower and motivate patients, promote their self-efficacy. ${ }^{20}$ This quality requirement is a prerequsite of $\mathrm{VC}$ in nursing that should be taken into account before determining whether VC meetings will be suitable or not. Another prerequisite for VC in nursing for home-dwelling patients is their knowledge of how to use the technological equipment. ${ }^{16,34,36,37,40}$ Over the last ten years, the findings explored that people have become more familiar with the technology.
Providing a small amount of training for the patients before use was considered adequate. However, these findings did not include the elderly, and more studies representing all age groups should be conducted, this in order to determine adequate training and use of the VC technology for each group and individual persons..$^{7,20}$

\section{Videoconferencing organization in nursing}

Utilizing VC seems to free up some other resources, such as the cost and time expended in traveling to the patient's home. Some studies found that patients preferred VC rather than having home visits; there were no need for preparing the house for visitors. Likewise, less travelling to meet the nurses were appreciated. By VC they felt less stress.

How VC adapted to the daily nursing schedule varied..$^{34-41}$ The differences in time and access for $\mathrm{VC}$ with the nurses varied according to the health situation and the nurses' tasks and possibilities for answer- ing. Whether patients are allowed to call the nurses for VC whenever they wish, within certain times or at specific times, is of significance both for patients and nurses. ${ }^{43}$ The variations points to the need for administrations to consider VC organization and scheduling in nursing before introducing it as a tool for nurse interaction with patients. Planning to use VC as a tool in person-centred nursing, the health-care providers and organization leaders should collaborate with nurses in decision-making about health system improvements. ${ }^{44}$ Implementing VC in person-centred care, the leadership should appreciate and take nurses' experiences, roles and attitudes into consideration. $^{45}$ When organizing $\mathrm{VC}$ usage, nursing care leaders also should consider the suitability of VC as a supplement or replacement for traditional nursing organization, and consider which kind of organization supports person-centred nursing. There is a need for more research about organizational topics that appeared from the study results.

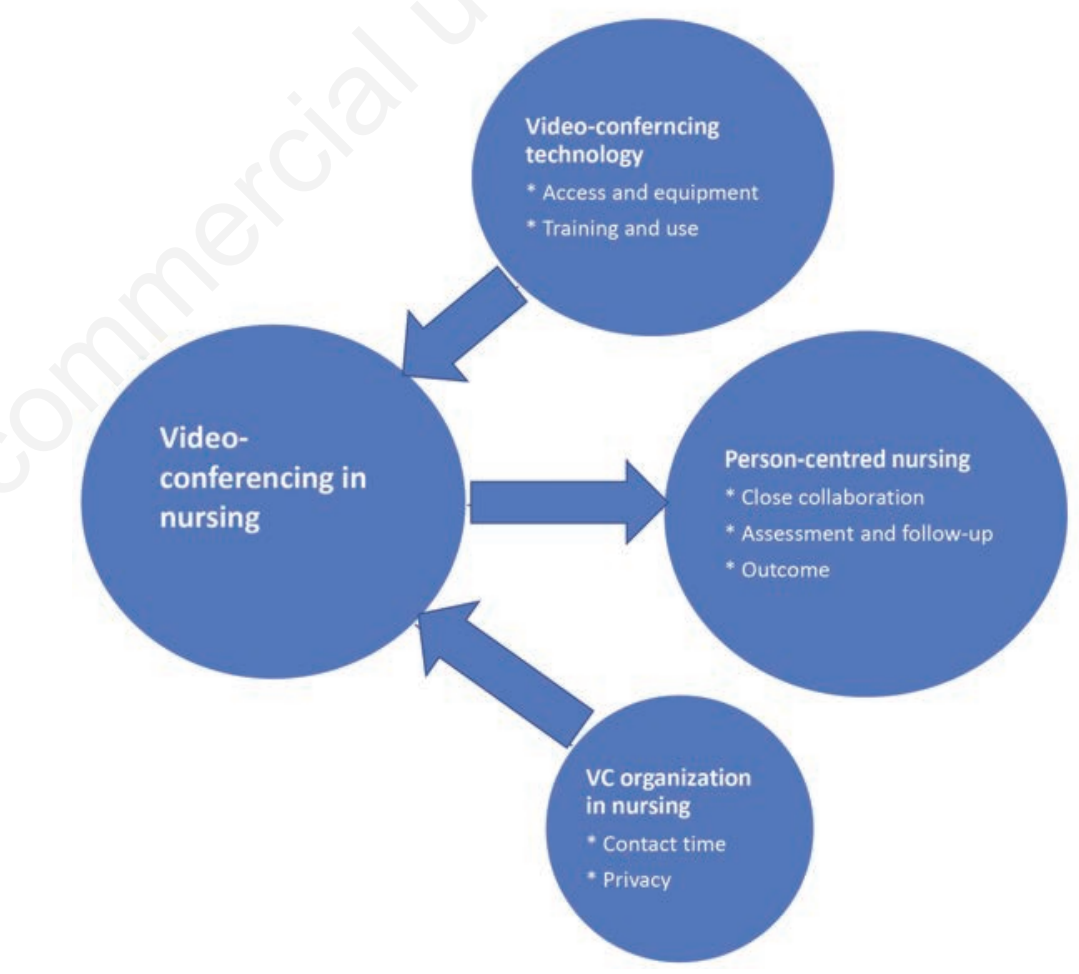

Figure 2. Suitability of videoconferencing in nursing described by three categories.

Table 2. Categories and subcategories.

\begin{tabular}{|c|c|c|c|}
\hline Categories & Videoconferencing technology & VC organization in nursing & Person-centred nursing \\
\hline \multirow[t]{2}{*}{ Subcategories } & Access and equipment & Contact time & $\begin{array}{l}\text { Close collaboration } \\
\text { Assessment and follow-up }\end{array}$ \\
\hline & Training and use & Privacy & Outcome \\
\hline
\end{tabular}




\section{Suitable person-centred nursing using videoconferencing}

Technology, user skills, and expedient $\mathrm{VC}$ organization in nursing will be prerequisites for uncomplicated use of VC. These factors are prerequisites in order to support person-centred nursing promoting patients' self-management. ${ }^{20,24}$

The analyses showed that VC can be both a supplement to and a replacement for ordinary care. ${ }^{34-41}$ Most studies consider VC to be an amendment. In order to meet future challenges, $7,8,10,12 \mathrm{VC}$ in nursing should be developed as a replacement of some of todays nursing. There is a need of more research on how best to replace ordinary care with $\mathrm{VC}$, and when suitable.

The nurses used VC for therapeutic, informational, supportive, and practical purposes. $^{34-41}$ Due to voice and body language that other e-Health technologies cannot provide, $\mathrm{VC}$ provided rich and deep conversations. ${ }^{38} \mathrm{VC}$ seems useful in person centred care seeing the patients as individuals, observing conditions and reactions, and cooperating on the development of health solutions. ${ }^{20,21,44}$ These results generally show VC to be suitable for patients and families in their homes. It appears to promote modern, patient-centred nursing which differs widely from earlier paternalistic trends ${ }^{20-22}$ and empowers patients and relatives, strengthening their self-efficacy and self-management in different health situations. ${ }^{24}$ Our results point on the need for more research on advantages and disadvantages the use of $\mathrm{VC}$ may have, regarding conversation quality, patient involvement and caring outcomes.

The nurses included in the studies were highly skilled and experienced, which might have contributed to the patients' sense of safety and confidentiality. In addition, patients and families generally met a familiar nurse in the VCs whom they had had contact with while in hospital. Both patients and nurses felt that VC conversations were more targeted and thorough than face-to-face conversations. Through VC, patients and families were able to take adequate responsibility for their health situations. VC seemed to support their self-management, and motivate and empower them. ${ }^{35}$ Other research underlines these results, $13,17-19,24$ in line with the philosophy of person-centred nursing. ${ }^{20}$ Suitability of VC should be considered in relation to nursing quality indicators ${ }^{46,47}$ and further researched.

Patients and their family were active in collaboration about their concerns, and allowed to contact nurses when they felt they needed. In this way, the patients had the defining power over the topic to be addressed. Thus, VC may contribute to patients' self-management in the health situations. ${ }^{24}$ Intrinsic motivation ${ }^{23}$ may be strengthen, and self-efficacy be a mechanism through which self-management interventions work. ${ }^{24}$ There may be a difference in health effects of pre-planned $\mathrm{VC}$ to the patients and VC when patients call when they feel in need. A new study showed that weekly planned VC between a palliative care group and patients with advanced cancer worsened the patients' symptom burden compared to a control group with traditionally follow up. ${ }^{43}$ More research is needed on the effect of $\mathrm{VC}$ organized with different appointments about contact times and who initiates the calls.

The relationship between the patients, families, and the nurses were described as confident and safe. ${ }^{34-41}$ Feeling safe may promote learning abilities, , $^{21,22,45}$ and learning in turn lead to self-management of health challenges. ${ }^{24,48}$ One study revealed that when provided with information about their health in a VC session, participants thereafter asked for more VC meetings. ${ }^{35}$ These findings are signs of patients becoming more proactive and self-managing in their recovery situations. The findings may indicate that $\mathrm{VC}$ is suitable in order to promote process and outcome quality of nursing. ${ }^{46,47}$ More research on patient outcomes of VC needed. The need for nursing assessment and follow-up can be quite different from one health situation to the next..$^{29,30}$ The results showed that patients in need of a high degree of monitoring required more VC meetings. It will be important to consider what kind of nursing and how much nursing the patient will need before determining whether VC will be beneficial. ${ }^{34,41}$ Such considerations will include matters of $\mathrm{VC}$ technology, organizing $\mathrm{VC}$ in nursing, and person-centred nursing - and reflections on the relationships between these matters. ${ }^{3}$ Decisions regarding the use of $\mathrm{VC}$ in health services also involves legal and ethical considerations. Nursing shall safeguard patient confidentiality and respect human rights. ${ }^{49,50} \mathrm{VC}$ between health personnel and patients must not be overheard by outsiders. Having facilities that cater for private VCs is essential, and was emphasized by the nurses. Findings are of health policy significance because patient empowerment and self-management are emphasized in today's policy documents and improvement strategies in both European countries and USA. ${ }^{11,49,51}$ This study points to the need for more research and nursing discussion worldwide on quality and ethics of $\mathrm{VC}$ in nursing.

\section{Method discussion}

This review of the VC literature sought systematization and validity through careful reasoning concerning the choices made during the study process. From the three databases scoured for relevant information, eight articles were found and included in the study. The few articles in the review encompassed mostly small studies of varying quality. For instance one of them did not describe the analysis method. ${ }^{41}$ They were from four countries with variety in populations. The studies were based on both qualitative and quantitative data and were set in quite different contexts, countries, and health systems. The articles contained data from very different nursing situations.

\section{Conclusions}

More knowledge gaps identified, there is a need of more research on how best to organize and use $\mathrm{VC}$ in future nursing. The study indicates VC to be suitable when network access and technology function properly, and the nursing is person-centred and well-planned in the healthcare organization. Use of $\mathrm{VC}$ seems to strengthen person-centred nursing, motivate patients and families, and promote their self-management. VC may act as a supplement to traditional nursing or it may represent a new development. Different organizational models of VC in nursing still need to be thoroughly tested. More research also needed to assess the suitability of $\mathrm{VC}$ in nursing for persons in different health situations.

Technology is rapidly developing globally. Research on VC in nursing must keep up with the technology development.

\section{References}

1. Kitamura C, Zurawel-Balaura L, Wong RKS. How effective is video consultation in clinical oncology? A systematic review. Curr Oncol 2010;17:17-27.

2. Paré G, Jaana M, Sicotte C. Systematic Review of home telemonitoring for chronic diseases: the evidence base. J Am Med Inform Assoc 2007;14:26977.

3. Rouleau G, Gagnon M-P, Côte J, et al. Impact of information and communication technologies on nursing care: results of an overview of systematic reviews. J Med Internet Res 2017;19: e122.

4. Khairat S, Wijesinghe N, Wolfson J, et al. Building a multicenter telehealth network to advance chronic disease 
management. In: Mantas J, Househ MS, Hasman A, eds. Integrating Information Technology and Management for Quality of Care Vol 202. Amsterdam: IOS Press; 2014. pp 299-302.

5. Carpenter GI. Aging in the United Kingdom and Europe - A Snapshot of the Future? . J Am Geriatr Soc 2005;53:310-3.

6. Cappelen $\AA$, Gjefsen H, Gjeldsvik M, et al. Forecasting demand and supply of labour by education Statistics Norway. Oslo; 2013.

7. United Nation Department of Economic and Social Affairs Populatopn Division. World Population Ageing 2015. New York; 2015.

8. Pomerleau J, Knaj C, Nolte E. The burden of chronic disease in Europe. In: Nolte E, McKee C, eds. Caring for people with chronic disease. A health system perspective. Berkshire: Open University Press; 2008.

9. Yach D, Hawkes C, Gould C, Hofman $\mathrm{K}$. The global burden of chronic disease: overcoming impediments to prevention and control. JAMA 2004;29:2616-22.

10. Gunter RL, Chouinard S, FernandesTaylor S, et al. Current use of telemedicine for post-discharge surgical care: a systematic review. J Am Coll Surg 2016;222:915-27.

11. HOD. Meld. St. nr. 47 Samhandlingsreformen. Oslo; 20082009.

12. Roelands M, Van Oost P, Depoorter AM. Service use in family caregivers of persons with dementia in Belgium: psychological and social factors. Health Social Care Commun 2008;16:42-53.

13. Logan MS, Ganster DC. The effects of empowerment on attitudes and performance: the role of social support and empowerment beliefs. J Manag Stud 2007;44:1523-50.

14. Lorig K, Seleznick M, Lubeck D, et al. The benefical outcomes of the arthritis self-management course are not adequately explained by behavior change. Arthr Rheum 1989;32:91-5.

15. Nijland N, Van Gemert-Pijnen J, Boer $\mathrm{H}$, et al. Evaluation of internet-based technology for supporting self-care: problems encountered by patients and caregivers when using self-care applications. JMIR 2008;10:e13.

16. Fronczek AE, Rouhana NA, Kitchin JM. Enhancing telehealth education in nursing: applying king's conceptual framework and theory of goal attainment. Nurs Sci Q 2017;30:209-213.

17. Ekman I, Sweberg K, Taft C, et al. Person-centered care - Ready for prime time Eur J Cardiovasc Nurs 2011;10: 248-51.

18. Leplege A, Gzil F, Cammellin M, et al. Person-centeredness: conceptual and historical perspectives. Disabil Rehabil 2007;29:1555-65.

19. Morgan S, Yoder LH. A concept analysis of person-centered care. J Holist Nurs 2012;30:6-15.

20. Mc Cance T, Mc Cormack B. The person-centered practice framework. In: Mc Cormack B, Mc Cance T, eds. Person-centered practice in nursing and health care. Theory and Practice. Oxford: Wiley Blackwell; 2017. pp 3664.

21. Gill PS. Patient engagement: an investigation at a primary care clinic. Int J Gen Med 2013;6:85-98.

22. Sepucha K, Uzogarra B, O'Connor M. Developing instruments to measure the quality of decisions: early results for a set of symptom-driven decisions. Patient Educ Counsel 2008;73:504-10.

23. Ryan R, Deci EL. Intrinsic and extrinsic motivations: classic definitions and new directions. Contemp Educ Psychol 2000;25:54-67.

24. Lorig KR, Holman HR. Self-management education: history, definition, outcomes, and mechanisms. Behav Med 2003;26:1-7.

25. Hibbard JH, Mahoney ER, Stock R, Tusler M. Do increases in patient activation result in improved self-management behaviors? Health Serv Res 2007;42:1443-63.

26. Ludman EJ, Peterson D, Katon W, et al. Improving confidence for self care in patients with depression and chronic illnesses. Behav Med 2013;39:1-6.

27. Wildewuur SE, Simonse LWL. Information and communication technology- enabled person-centered care for the "big five" chronic conditions: scoping review. J Med Internet Res 2015; 17:e77.

28. Boodley CA. Primary care telehealth practices. J Am Acad Nurse Pract 2006;18:343-5.

29. Tschirch P, Walker G, Calvacca LT. Nursing in Tele-Mental Health. J Psychosoc Nurs 2006;44:20-7.

30. Varghese SB, Phillps CA. Caring in Telehealth. Telemed e-Health 2009; 15:1005-9.

31. Sevean P, Dampier S, Spadoni M, Strickland S, Pilatzke S. Bridging the distance: educating nurses for telehealth practice. J Contin Educ Nurs 2008;39:413-8.

32. Hsieh H-F, Shannon SE. Three approaches to qualitative content analysis. Qual Health Res 2005;15:1277-88.
33. Vaismoradi M, Turunen $\mathrm{H}$, Bondas $\mathrm{T}$. Content analysis and thematic analysis: Implications for conducting a qualitative descriptive study. Nurs Health Sci 2013;15:398-405.

34. Katz M, Slack R, Bruno M, et al. Outpatient virtual clinical encounters after complex surgery for cancer: a prospective pilot study of "TeleDischarge". J Surg Res 2016;202:196-203.

35. Seguranyes G, Costa D, FuentelsazGallego C, et al. Efficacy of a videoconferencing intervention compared with standard postnatal care at primary care health centres in Catalonia. Midwifery 2014;30:764-71.

36. Lindberg I, Öhrling K, Christensson K. Midwives' experience of using videoconferencing to support parents who were discharged early after childbirth. J Telemed Telecare 2007;13:202-5.

37. Lindberg I, Christenson K, Öhrling K. Parents' experiences of using videoconferencing as a support in early discharge after childbirth. Midwifery 2009;25:357-65.

38. Carter EL, Nunlee-Bland G, Callender C. A patient-centric, provider-assisted diabetes telehealth self-management intervention for urban minorities. Perspect Health Info Manag 2011;8.

39. Skär L, Söderberg S. The use of information and communication technology to meet chronically ill patients' needs when living at home. Open Nurs J 2011;5:74-8.

40. Lindberg B, Axelsson K, Öhrling K. Experience with videoconferencing between a neonatal unit and the families' home from the perspective of certified paediatric nurses. J Telemed Telecare 2009;15:275-80.

41. Bensink M, Armfield N, Irving H, et al. A pilotstudy of videotelephone-based support for newly diagnosed paediatric oncology patients and their families. J Telemed Telecare 2008;14:315-21.

42. Mallow JA, Petitte T, Narsavage G, et al. The use of video conferencing for persons with chronic conditions: a systematic review. E-Health Telecommun Syst Networks 2016;5:39-56.

43. Hoek P, Schers HJ, Bronkhorst EM, et al. The effect of weekly specialist palliative care teleconsultations in patients with advanced cancer - a randomized clinical trial. BMC Med 2017;15.

44. Sharma T, Bamford M, Dodman D. Person-centred care: an overview of reviews. Contemp Nurse 2015;51:10720.

45. Senge PM. The fifth discipline: the art and practice of the learning organiza- 
tion. Chatham, Kent: Random House Business Books; 2006.

46. Donabedian A. The quality of care: How can it be assessed? JAMA 1988;260:1743-8.

47. Donabedian A. The role of outcomes in quality assessment and assurance. Qual
Rev Bull 1992;11:356-60.

48. Akritidou S, Husted GR, Kazakos K, Olesen K. The effect of using interactive communication tools in adults with type-2 diabetes. Nurs Rep 2017;1-3.

49. Government N. Patients' Rights Act 1999; 2011.
50. International Council of Nurses. The ICN code of ethics for nurses. Geneva, Switzerland; 2012.

51. Taylor D, Bury M. Chronic illness, expert patients and care transition. Sociol Health Illn 2007;29:27-45. 